\title{
Reach and messages of the world's largest ivory burn
}

(1) Alexander Braczkowski ${ }^{1,2 *}$, Matthew H Holden ${ }^{3}$, Christopher O’Bryan ${ }^{1}$, Chi-Yeung Choi $^{3}$, Xiaojing $\mathrm{Gan}^{3}$, Nicholas Beesley ${ }^{4}$, Yufang Gao ${ }^{5}$, James Allan ${ }^{1,3}$, Peter Tyrrell ${ }^{6}$, Daniel Stiles ${ }^{7}$, Peadar Brehony $^{8}$, Revocatus Meney ${ }^{1}$, Henry Brink ${ }^{9}$, Nao Takashina ${ }^{10}$, Ming-Ching Lin ${ }^{11}$, Hsien-Yung Lin ${ }^{3}$, Niki Rust ${ }^{12}$, Severino G. Salmo III ${ }^{13}$, James EM Watson ${ }^{1,14}$, Paula Kahumbu ${ }^{15}$, Martine Maron ${ }^{1}$, Hugh P Possingham $^{3} \&$ Duan Biggs $3,16,17$

${ }^{1}$ School of Earth and Environmental Sciences, The University of Queensland, Brisbane QLD 4072, Australia; ${ }^{2}$ School of Natural Resource Management, Nelson Mandela Metropolitan University, George Campus, George, South Africa, ${ }^{3}$ ARC Centre of Excellence for Environmental Decisions, Centre for Biodiversity \& Conservation Science, The University of Queensland, Brisbane QLD 4072, Australia; ${ }^{4}$ Meltwater, Level 26 Waterfront Place, 1 Eagle Street, Brisbane QLD 4000, Australia; ${ }^{5}$ School of Forestry and Environmental Studies, Yale University, USA; ${ }^{6}$ South Rift Association of Landowners, PO BOX 15289-00509, Nairobi, Kenya; ${ }^{7}$ Ol Pejeta Conservancy, Kenya; ${ }^{8}$ PAMS Foundation Tanzania, Arusha PO Box 16556, Tanzania; ${ }^{9}$ Brink Eco Consult, Queensland 4121, Australia; ${ }^{10}$ Tropical Biosphere Research Center, University of the Ryukyus, 3422 Sesoko Motobu, Okinawa 9050227, Japan; ${ }^{11}$ Institute of Ecology and Evolutionary Biology, National Taiwan University, Taipei City, 10617, Taiwan; ${ }^{12}$ World Wildlife Fund, Rufford House, Surrey, GU21 4LL, UK; ${ }^{13}$ Department of Environmental Science, Ateneo de Manila University, Loyola Heights, 1108 Quezon City, Philippines, ${ }^{14}$ Wildlife Conservation Society, 2300 Southern Boulevard, Bronx, New York, ${ }^{15}$ Wildlife Direct, Kenya, ${ }^{16}$ Environmental Futures Research Institute. Griffith University, Nathan Queensland, 4111, Australia, ${ }^{17}$ Department of Conservation Ecology and Entomology, Stellenbosch University, Private Bag X1, Matieland 7602 , South Africa

This article has been accepted for publication and undergone full peer review but has not been through the copyediting, typesetting, pagination and proofreading process, which may lead to differences between this version and the Version of Record. Please cite this article as doi: 10.1111/cobi.13097.

This article is protected by copyright. All rights reserved. 
*Corresponding author: alexander.braczkowski@gmail.com

Keywords: Africa, Elephant, Conservation marketing, Ivory burn, Media reach

Running head: Ivory burn

Article impact statement: Key ivory-using states largely support banning of the ivory trade.

\begin{abstract}
Recent increases in ivory poaching have depressed African elephant populations. Successful enforcement has led to ivory being stockpiled. Stockpile destruction is becoming increasingly popular, and most destruction has occurred in the last five years. Ivory destruction is intended to send a strong message against ivory consumption, both in promoting a taboo on ivory use and catalyzing policy change. However, there has been no effort to establish the distribution and extent of media reporting on ivory destruction events globally. We analyze media coverage across eleven important nation states of the largest ivory destruction event in history (Kenya, 30 April 2016). We used a wellaccepted online media crawling tool and key language translations to search online and print newspapers. We found most online news on the ivory burn came from the US ( $81 \%$ of articles), while print news was dominated by Kenya (61\% of articles). We subjected online articles from five key countries and territories to content analysis and found $86-97 \%$ of all online articles reported the burn as a positive conservation action, while between $4-50 \%$ discussed ivory burning as having a negative impact on elephant conservation. Most articles discussed law enforcement and trade bans as effective for elephant conservation. There was more relative search interest globally on the 2016 Kenyan ivory burn than any other in five years. Our study is the first attempt to track the spread of media around an ivory burn and is a case study in tracking the effects of a conservation-marketing event.
\end{abstract}

This article is protected by copyright. All rights reserved. 


\section{Introduction}

African elephant (Loxodonta spp.) conservation has been bolstered by recent commitments made by the United States, France, and China to close down their legal ivory markets in 2016 (Yu et al. 2016). These follow widespread African elephant declines caused by the most significant poaching since the 1989 ivory ban (Chase et al. 2016). An estimated 144000 elephants were killed between 2007-2014 across sub-Saharan Africa (Chase et al. 2016). Resultantly, elephants are increasingly threatened across much of their range. Stakeholders in African elephant management broadly agree that this poaching surge is the result of a renewed wave of demand for ivory products (CITES 2016).

In 1989 , Kenya took action against the ivory trade by burning 12 tons of ivory in a public spectacle in the country's capital (Schiffman 2016). Since then, 20 other countries have followed suit, including many elephant range states contributing to a total of 29 destruction (burn and crush) events. Most of these have occurred since 2011 and a total of 256 tons of ivory have been burnt and crushed, that is approximately a quarter of Africa's total ivory stockpile (CITES 2016). The largest ivory destruction event in history took place in Kenya on 30 April, 2016 where over 105 tonnes of ivory was burned (Biggs et al. 2016).

There are a number of key reasons for burning ivory including: 1) it is an awareness and publicity campaign (Schiffman 2016), 2) it sends a message to poachers and consumers that elephant poaching is intolerable (Schiffman 2016), 3) destruction reduces the available supply of ivory (Kahumbu and Halliday 2016) and 4) it demonstrates a stand against the ivory trade (Laing 2016) (Figure 1). Burning ivory forms an important component of a broader campaign, which attempts to stigmatize its use. However, ivory stockpile destruction could produce unintended outcomes. If ivory price increases with rarity, then reducing supply through destruction events could theoretically increase elephant extinction risk (Holden and McDonald-Madden 2017). Unfortunately, there is no empirical evidence 
that confirms or refutes this concern (Biggs et al. 2016). Because destroying ivory in such spectacles could potentially aid or hinder elephant conservation, it is essential to monitor their impact on elephant poaching and ivory trafficking (Biggs et al. 2016). While this is a difficult task, due to uncontrollable confounding factors, analyzing the reach of media coverage is an important first step. The ability of ivory burns and crushes to spread a strong message that reduces poaching and trafficking may rely on the effectiveness of media reporting, including spread and content.

Achieving these objectives may rely in part on the effectiveness of media reporting, including spread and content. Given the increasing popularity of ivory destruction, it is surprising that limited information is available on the media covering these events, and little is known about their true impact. Here we present the first assessment media coverage reporting on the 30 April 2016 ivory burn in Kenya. We track the number of online and print news articles in key ivory consumer, African elephant range, and wildlife charity countries, report on the relative Google search interest of the term "ivory burn" over five years globally and compare the content of news originating from the major ivory consumer states and the UK and USA.

\section{Methods}

We assessed online and print media coverage of the ivory burn in 11 countries important for elephant conservation and the ivory trade. First, we selected Mainland China, Hong Kong, Thailand, Vietnam, Taiwan, Philippines, and Japan - these are the most prominent ivory consumer states. Second, we assessed coverage in Tanzania, where most savannah elephant poaching has occurred in the last eight years (Chase et al. 2016) and Kenya, where the ivory burn on 30 April 2016 was carried out. Third, we assessed coverage in the USA, and UK where the vast majority of animal welfare (e.g. International Fund for Animal Welfare) and conservation NGOs that work on elephant conservation

This article is protected by copyright. All rights reserved. 
in Africa (e.g. Zoological Society of London and Wildlife Conservation Society) are headquartered. In addition, we assessed relative internet search interest for the term "ivory burn" globally (198 states with Google access), over a five-year period to assess whether the 30 April 2016 burn received more relative search interest compared to previous burns.

\section{Spread of media coverage}

\section{Online news sources}

We used a "Big Data" analysis approach through the online media crawling tool of the Meltwater Group, one of the world's largest media monitoring companies (Meltwater 2016). The crawling tool has been used in previous studies to collect online news data on issues ranging from the conservation of African lions Panthera leo (e.g. Macdonald et al. 2016) to public attitudes towards police in Finland (e.g. Kääriäinen et al. 2016). The crawling tool uses an automated algorithm that search news articles from over 275314 news sources globally (Macdonald et al. 2016). The search covers 91 languages and at least one million authors. We used the Boolean search terms "ivory", "Kenya" and "burn" in English for each state and also translated these terms into the most commonly spoken language in each of our countries of interest. We limited our search to articles strictly with these keywords in their titles or within their first paragraph (Supporting Information 1). We did this as some articles only made short mentions of matters pertaining to the ivory burn in Kenya and had little to do with the context of ivory usage or elephant conservation. Our sampling period encompassed 106 days (1 April 2016-15 July 2016), which covered information over the month building up to the event and two and a half months after it. We quantified the total number of articles published per state, the total sources searched per state and a metric of media saturation (Macdonald et al. 2016), which is simply the number of articles divided, by the total number of news sources per state.

This article is protected by copyright. All rights reserved. 


\section{Print media sources}

To supplement our online media analysis, we examined the five largest print newspapers (by circulation) in each state of interest. For Mainland China (the main consumer market of ivory; Stiles et al. 2015), we considered the five largest newspapers in three key regions, 1) Hong Kong, 2) Mainland China overall and 3) Beijing city (China's capital). The majority of media attention across both print and online news centered on the day of the ivory burn (30 April 2016) but we tracked print articles one week before and after the event (Figure S1). Our print newspaper-sampling window was therefore 15 days from 23 April-7 May 2016. We examined the total number of articles published in each state and a metric of media saturation (articles divided by total number of newspapers sampled; Macdonald et al. 2016). We were also interested in the prominence of the ivory burn as a news item. We, therefore, noted the page number on which articles appeared, the relative size of articles $(2,1,3 / 4$, $1 / 2,1 / 3,1 / 4$ or $<1 / 4$ page) and whether the article was accompanied by a photograph. We also noted additional pictorial stories and paid advertisements pertaining to the event.

\section{Relative search interest}

We were also interested in how Internet search activity about ivory burns in general changed around the time of the 2016 ivory burn. Google Trends provides an indicator of internet user searches over time (Ladle et al. 2016) and has been widely applied in studies on the popularity of environmental topics (Nghiem et al. 2016; Ficetola 2013). We downloaded data on relative internet search interest of users for the search term "ivory burn" globally (198 nations with Google access). We used Google Trends "Explore" function and input the terms ivory burn (no quotations), assessing relative search interest over approximately five years (1820 days; 11 Sept 2011- 4 Sept 2016) to compare attention at the time of the 30 April burn compared to previous burns. The reported numbers are scaled on a range

This article is protected by copyright. All rights reserved. 
of $0-100$, as a percentage of total searches in a given location and time period (Ladle et al. 2016; Google 2016).

\section{Content of media coverage}

\section{Media content analysis}

We supplemented our analysis of media coverage with content analysis. We examined the discourse of articles in a selection of countries from our sample. Taiwan, a smaller ivory consumer known to serve as a transition point in ivory shipments (Underwood et al. 2013), featured highly in our media coverage assessment, so we, assessed the content of online articles from Mainland China, Hong Kong, UK, USA and Taiwan. We followed the media content approach described by Macnamara (2005) and Gao (2014) and coded articles into different categories. Using the sample of recovered articles from our online news sources, four authors (Choi, Braczkowski, Gan and O' Bryan) each coded 20 randomly selected articles and followed an a priori coding protocol of major article themes, the framing of the ivory trade, and the individuals or stakeholders quoted in the articles (see Table 1 for a full description) (Bhatia et al. 2013). We selected the 50 highest reaching online news articles per state but, because our analysis was done post hoc to the ivory burn event, some article hyperlinks had expired. We, therefore, only provided content analysis for unique articles (removing duplicates per state) with functional hyperlinks (Supporting Information 2). Media content categorization or "coding" requires consensus amongst at least two individuals (Lombard et al. 2002). We used Cohen's Kappa to assess the agreement between each of our two state-specific coders (Choi and Gan for Chinese, Hong Kong and Taiwan samples and Braczkowski and O' Bryan for the UK and USA samples; Geertzen and Hunt 2009, Gao et al. 2016). Results of the data were only accepted with Kappa values of 0.7 or above. This represents an adequate level of consensus among coders beyond chance (Lombard et al. 2002).

This article is protected by copyright. All rights reserved. 


\section{Results}

\section{Spread of media coverage}

\section{Online news sources}

We sampled 122647 online news sources and found a total of 1944 articles from our 11 states of interest (Figure S2). Online news coverage of the ivory burn was strongest in the UK and USA. The majority of articles came from the USA (81\%), which also featured the highest number of individual sources searched (59\%). Taiwan (82 articles), the UK (76 articles) and Mainland China (61 articles) followed but collectively only made up $11 \%$ of total articles. Notably, Taiwan had 21 more articles than Mainland China despite having 96\% fewer sources searched. Additionally, 59\% of all Chinese articles $(n=36 / 61)$ were written in English. This was lower in other states (e.g. 20\% of Hong Kong sample; Figure S3). Media saturation (articles/total sources) was highest in the states of Kenya, Tanzania and Taiwan (Figure S4).

\section{Print media sources}

We searched a total of 885 daily editions, including weekend editions, from 59 unique newspapers over the 15-day period from eleven states (12 regions, Figure S4). This yielded a total of 96 articles detailing information pertaining to the 30 April ivory burn event in Kenya, the highest of any country. We also found four pictorials (a photo feature), six adverts, and two cartoons (all from Kenya). Print news on the ivory burn peaked from 29 April-2 May 2016 (65\% of all articles). Kenya had the highest number of articles printed in its five largest newspapers (61\% of all articles), followed by the UK (9\%) and Mainland China (7\%; Figure S4). There were no news articles recovered from the five largest print newspapers in Vietnam, and there was only one recovered from the Hong Kong sample. Print media saturation around the event was highest in Kenya, between seven and 47 times the This article is protected by copyright. All rights reserved. 
saturation in other countries investigated (Figure S4). The mean page number where articles were found was 15 , and $73 \%$ of all articles had an accompanying photograph. The majority of articles (76\%) were a half a page long or less. Six articles made the front page (two from the UK, two from Kenya, one from Tanzania and one from Japan).

\section{Relative search interest}

Our examination of the search terms "ivory burn" in Google Trends showed that no ivory burn event over the previous five years attracted as much search interest as the one on the 30 April 2016 (Figure S5).

\section{Content of media coverage}

We coded a total of 140 articles that had functional hyperlinks at the time of data collection (UK $\mathrm{n}=44$; US $\mathrm{n}=49$; Mainland China $\mathrm{n}=21$; Hong Kong $\mathrm{n}=7$ and Taiwan $\mathrm{n}=19$ ), removing any duplicates in each state sample. Notably, $76 \%$ of our Chinese content analysis sample $(15 / 21$ articles) was written in English. Our inter-coder reliability estimates derived from Cohen's Kappa analysis were all above $0.7(\mathrm{UK}=0.80 ; \mathrm{US}=0.83 ; \mathrm{CH}=0.79 ; \mathrm{HK}=0.73$ and $\mathrm{TW}=0.73)$. The majority of articles in our content analysis for all regions reported on the ivory burn as something that was seen as a positive action for elephant conservation (range=86-98\%; Table 2) but Hong Kong and Taiwan had higher incidence of discussions in articles on negative consequences of burning ivory (50 and 32\% respectively vs. 16,9 and $5 \%$ for the UK, US and Mainland China respectively). In most cases, articles that discussed these negative consequences made reference to economists and consultants who thought burning ivory would increase its price. Very few articles discussed legal ivory trade as a legitimate activity that could be regulated (range $=3-10 \%$ ) and the majority of articles cited trade enforcement and anti-poaching as conservation solutions (range $=55-100 \%$ ). This occurrence was 
higher in Mainland China, Hong Kong and Taiwan (range=76-100\%) vs. the UK (55\%) and USA (62\%). Where individuals were quoted or interviewed in the articles, the majority were government officials (57\%).

\section{Discussion}

Ours is the first study to analyze media coverage and content surrounding the largest ivory destruction event in history (Kenya, April $30^{\text {th }}$ 2016). We found media coverage was greater than previous ivory destruction events. However, coverage was not uniform as online media coverage was much greater in the USA than in East Asia, and coverage in print media was predominantly limited to East Africa. Since news coverage of the burn was not well represented in some consumer states, there may be opportunities to better target conservation messages related to future ivory destruction events. Our content analysis showed ivory destruction was largely reported as a positive conservation action, suggesting the message communicated through the media was in line with the overall objectives of the ivory burn such as demonstrating a stand against the ivory trade and contributing to a broader campaign of stigmatizing the use of ivory.

\section{Spread of global news}

Media coverage was greatest in the USA which is unsurprising since it has the largest number of media sources (Chyi and Sylvie 2001) and has been closely involved in recent African Elephant conservation efforts. The US is also the base of major NGOs working in Africa and many high-profile individuals in Western societies have played crucial roles in increasing media and public interest in conservation, which may account for the relatively high coverage.

This article is protected by copyright. All rights reserved. 
Mainland China, the primary consumer of ivory, had relatively low online media coverage. It is plausible that the three-day Chinese Labor Day, celebrated from April $30^{\text {th }}-$ May $2^{\text {nd }}$, which directly overlapped with the burn, subsequently dominated the coverage. Contrastingly, Mainland China had one of the highest print media saturation levels when adjusted for sampling bias. This also indicates that timing is important when choosing the date of an ivory destruction event.

Interestingly, Taiwan showed a high media saturation relative to its size and the number of online news sources. Taiwan is considered a transit point for the ivory trade and it did experience a $40 \%$ increase in worked ivory between 2010 and 2011 (Underwood et al. 2013). The high incidence of online news in Taiwan could be owed to the fact that it has one of the highest freedom of the press in Asia and the longest history in publishing Chinese-language online newspapers, The China Times (Chyi and Huang 2011). According to a recent survey on media use, the internet has become the second largest source for news (46.55\% of the respondents aged 11 and above) in Taiwan after television (59.33\%; Rainmaker XLM, 2016).

\section{Content of news detailing the ivory burn}

Our results suggest that both western states and key ivory consuming states reported on the ivory burn as a positive action for elephant conservation. Additionally, there was overwhelming support for ivory trade bans and anti-poaching as solutions to the poaching crisis. This is in line with what could be expected from local media narratives, because 22 of the 183 (and 8/11 in this analysis) CITES member states (including the largest ivory markets China and Hong-Kong) have implemented ivory destruction since 1989. Moreover, these narratives largely support Mainland China and Hong Kong's recent pledges to phase out commercial ivory trade by the end of 2017 and 2021 respectively (Cheung et al. 2017; Actman 2016; Yu et al. 2016; Neme 2016). The only worrying result we found for the 
Chinese and Hong Kong samples was that few online articles we analyzed for message content were printed in English. This was $59 \%$ for the Chinese sample and $20 \%$ for the Hong Kong sample respectively. This is notable as a low proportion of the Chinese population reads English and hence the actual population who read the articles may be lower than our results predict. This could be owed at least partly to a failure of the Meltwater search engine to account for smaller Chinese newspapers.

\section{Caveats and other ivory burn news channels}

Our study has made the first attempt to track the spread of global written news on history's largest ivory burn event through two key avenues (online news and print news). However, there are some caveats. First, although we used the most powerful media crawling tool available commercially, we cannot be certain that it did not miss the smaller online news outlets. Second, our content analysis featured a small sample size, and also failed to assess how members of the public responded to messages being sent. Third, we did not track news sent through radio, television and social media. It is possible that these forms of media have great sway in reaching the mass public. For example, on the 23 April 2017 the African Wildlife Foundation generated over 600 million impressions about the burn on Twitter, reaching an estimated 130 million unique accounts (Paula Kahumbu pers.comm). This and other social media posts on Twitter and Facebook with the hashtags \#LightAFire, \#WorthMoreAlive, \#StopTheTrade and \#Tweet4Elephants were actively shared by several NGOs (e.g. Save the Elephants, National Geographic Society and WCS) as well as government entities (e.g. Kenya Wildlife Service) during the Giants Club Summit (see: http://spaceforgiants.org/giantsclub/summit/; 28th - 30 April) and the ivory burn on 30 April 2016. The \#WorthMoreAlive hashtag on Twitter, for example, was shared the most in Kenya, the UK and USA, with far less coverage in far east Asia (see: http://www.techweez.com/2016/05/06/twitter-map-of-the-ivory-burn-in-kenya/). It is possible, and in fact likely, that there was considerable social media activity on Weibo, the Chinese equivalent of Twitter, having 313 million MAU's and 139 million average DAU's in December 2016 
(http://media.corporate-ir.net/media_files/IROL/25/253076/WeiboCorp_20F_20170427.pdf).

cannot rule out that the low incidence of media coverage (particularly from online news sources) in China could also be owed to the country's limitations on the freedom of press (King et al. 2013). However, with China's recent policy pledges at the highest government levels to ban the domestic ivory trade we doubt Chinese authorities would intentionally restrict the quantity of news articles being published on the ivory burn. Finally, we feel that we would have ideally also provided a percentage of ivory burn articles of total articles, but if the distribution of total articles in each news source varies systematically between countries hen our results could be misleading, however total potential sources is the best data we have and should at least approximately be reasonably correlated with the total number of all articles published in these sources.

\section{Suggestions on future attempts to track global conservation events and}

\section{importance for conservation messaging}

The year 2016 was a seminal one for African elephant conservation and the ivory trade. African elephants and the ivory trade were prominent in discussions at the World Conservation Congress and the $17^{\text {th }}$ Conference of the Parties to the Convention on the Trade in Endangered Species (CITES). In addition, shortly after the Kenyan burn in April, the United States and France committed to near total bans of their domestic ivory markets (2 June and 2 August 2016 respectively, and President Obama originally made the pledge in September 2015 during President Xi's US visit where Xi, on the same occasion, declared China's intention to close its domestic ivory market), a policy action, which is now comparable to other EU states.

We argue that the staging of ivory destruction events could be improved to ensure messages reach all the relevant demographics. If policy makers are the demographic targeted by ivory burning (i.e.

This article is protected by copyright. All rights reserved. 
witnessing the spectacle and reading about it), then timing of destruction events should be around key meetings and more leaders of source, transit and demand countries be invited to attend them. If ivory consumers, poachers and dealers are the intended recipients of news on ivory burns, we suggest that an intelligent media strategy be developed to lengthen the period of news coverage to weeks or months to draw out the messages and maximize coverage in print, radio and online media within ivory consumer states by local NGO's and governments within consumer countries. Major opportunities to reach mass public in ivory consumer states include public holidays and other events with the potential to affect the spread of news. The reach of a news story can also be enhanced by involving celebrities who are recognized in the target communities (Duthie et al. 2017).

Further attempts to track the spread and content of media reporting on ivory destruction are necessary to better plan these events in future. For example, the Project Ocean Partnership (a campaign to raise awareness about overfishing, change eating habits of consumers and raise money for marine reserves) between the Zoological Society of London and the department store Selfridges tracked outreach metrics of printed and online articles, blogs, radio and television (they estimated that through all of these media channels, some 400 million people were reached during the campaign in 2011 ; Wright et al. 2015). Our work adds some elements for a case study in the emerging field of conservation marketing, which has been cited as a powerful tool which could be used to change the behaviour and attitude of the public towards wildlife products (Veríssimo et al. 2016; Wright et al. 2015; Veríssimo et al. 2011; Smith et al. 2010). However future studies should explicitly factor in the behavioral response of the intended target audiences and make more effort in identifying who the target audience is. 
The spectacle of ivory burns have been a prominent part of efforts to conserve the African elephant to date, and will likely remain so. Conservation interventions, whether they are related to illegal wildlife trade or other drivers of biodiversity loss, ideally should be evidence-based, and to do that (and to be more effective in future) could include monitoring and evaluation as part of their design (e.g. Wright et al. 2015). We recommend that governments, scientists and key elephant management policy makers follow our lead in attempting to track the spread and content of conservation events such as the 30 April 2016 ivory burn in order to understand impact and refine strategies. The results from this study can be used to ensure that the desired messages from future ivory burning events have a broader reach and are more effectively targeted to their audiences, to achieve better conservation outcomes. Finally, it is imperative that budgets dedicated to ivory destruction include an investment for monitoring and evaluation of impact.

\section{Acknowledgments}

We are grateful to the Meltwater Group for assistance with the crawling tool and sourcing data. We are grateful for a grant from the ARC Centre of Excellence for Environmental Decisions, University of Queensland for a grant to perform the analysis.

\section{References}

Bhatia, S., Athreya, V., Grenyer, R., \& Macdonald, D. W. (2013). Understanding the Role of Representations of Human-Leopard Conflict in Mumbai through Media-Content Analysis. Conservation Biology, 27(3), 588-594.

This article is protected by copyright. All rights reserved. 
Biggs, D., Holden M.H., Braczkowski A., \& Posssingham H.P. (2016). Elephant poaching: Track the impact of Kenya's ivory burn. Nature, 534(7606), 179-179.

Chase, M. J., Schlossberg, S., Griffin, C. R., Bouché, P. J., Djene, S. W., Elkan, P. W., ... \& Omondi, P. (2016). Continent-wide survey reveals massive decline in African savannah elephants. PeerJ, 4, e2354.

Cheung, H., R. W. Wong, and D. Biggs. 2017. Ivory ban: Close Hong Kong's ivory-trade window. Nature, 544, 35-35.

Chyi, H. I., \& Sylvie, G. (2001). The medium is global, the content is not: The role of geography in online newspaper markets. The Journal of Media Economics, 14(4), 231-248.

Chyi, H. I., \& Huang, J. S. (2011). Demystifying the demand relationship between online and print products under one newspaper brand: the case of Taiwan and the emergence of a universal pattern, Asian Journal of Communication, 21:3, 243-261.

CITES. (2016). Document 57.5 of the Seventeenth meeting of the conference of the Parties. Johannesburg, South Africa.

This article is protected by copyright. All rights reserved. 
Duthie, E., Veríssimo, D., Keane, A., \& Knight, A. T. (2017). The effectiveness of celebrities in conservation marketing. PLoS one, 12(7), e0180027.

Ficetola, G. F. (2013). Is interest toward the environment really declining? The complexity of analysing trends using internet search data. Biodiversity and conservation, 22(12), 2983-2988.

Gao, Y., Stoner, K. J., Lee, A. T., \& Clark, S. G. (2016). Rhino horn trade in China: An analysis of the art and antiques market. Biological Conservation, 201, 343-347.

Gao, Y. (2014) Elephant ivory trade in China: Comparing different perspectives. The bulletin of the Yale Tropical Resources Institute, 32-33, 101-107.

Geertzen, J., \& Bunt, H. (2009, July). Measuring annotator agreement in a complex hierarchical dialogue act annotation scheme. In Proceedings of the 7th SIGdial Workshop on Discourse and Dialogue (pp. 126-133). Association for Computational Linguistics.

Holden, M.H. and McDonald-Madden, E., 2017. High prices for rare species can drive large populations extinct: the anthropogenic Allee effect revisited. Journal of theoretical biology, 429, pp.170-180.

Kahumbu, P. \& Halliday, A. (2016). Why it makes sense to burn ivory stockpiles. The Guardian, 23 April.

This article is protected by copyright. All rights reserved. 
King, G., Pan, J., \& Roberts, M. E. (2013). How censorship in China allows government criticism but silences collective expression. American Political Science Review, 107(2), 326-343.

Kääriäinen, J., Isotalus, P., \& Thomassen, G. (2016). Does public criticism Erode trust in the police? The case of Jari Aarnio in the Finnish news media and its effects on the public's attitudes towards the police. Journal of Scandinavian Studies in Criminology and Crime Prevention, 17(1), 70-85.

Ladle, R. J., Correia, R. A., Do, Y., Joo, G. J., Malhado, A., Proulx, R., ... \& Jepson, P. (2016).

Conservation culturomics. Frontiers in Ecology and the Environment, 14(5), 269-275.

Lombard, M., Snyder-Duch, J., \& Bracken, C. C. (2002). Content analysis in mass communication: Assessment and reporting of intercoder reliability. Human communication research, 28(4), 587604.

Macdonald, D. W., Jacobsen, K. S., Burnham, D., Johnson, P. J., \& Loveridge, A. J. (2016). Cecil: A Moment or a Movement? Analysis of Media Coverage of the Death of a Lion, Panthera leo. Animals, 6(5), 26.

Macnamara, J. R. (2005). Media content analysis: Its uses, benefits and best practice methodology. Asia-Pacific Public Relations Journal, 6(1), 1.

This article is protected by copyright. All rights reserved. 
Meltwater. (2016). Available online: http://www.meltwater.com/products/

Nghiem, L. T., Papworth, S. K., Lim, F. K., \& Carrasco, L. R. (2016). Analysis of the Capacity of Google Trends to Measure Interest in Conservation Topics and the Role of Online News. PloS one, 11(3), $\mathrm{e} 0152802$.

Rainmaker XLM (2016). Report on Media use survey, Retrieved from http://www.xkm.com.tw/HTML/report/rngresearch/2016Q1RNMM.pdf

Schiffman, R. (2016). Why Kenya is burning 100 tons of elephant ivory. Scientific American, April 27.

Smith, R.J., Veríssimo D., MacMillan D.C. (2010) Conservation and marketing: how to lose friends and influence people. Pages. 215-232 in N. Leader-Williams, W.M. Adams, R.J.

Smith editors. Trade-offs in conservation: deciding what to save. Wiley-Blackwell, Oxford, UK .

Stiles, D., Martin, R. \& Moyle, B. (2015). Analysis of Ivory Demand Drivers. Report prepared for the Wildlife Conservation Society, Beijing, China Office.

This article is protected by copyright. All rights reserved. 
Underwood, F. M., Burn, R. W., \& Milliken, T. (2013). Dissecting the illegal ivory trade: an analysis of ivory seizures data. PloS one, 8(10), e76539.

Veríssimo, D., \& McKinley, E. (2016). Introducing conservation marketing: why should the devil have all the best tunes?. Oryx, 50(1), 14 .

Veríssimo, D., MacMillan, D. C., \& Smith, R. J. (2011). Toward a systematic approach for identifying conservation flagships. Conservation Letters, 4(1), 1-8.

Wright, A. J., Veríssimo, D., Pilfold, K., Parsons, E. C. M., Ventre, K., Cousins, J., ... \& McKinley, E. (2015). Competitive outreach in the 21 st century: why we need conservation marketing. Ocean \& Coastal Management, 115, 41-48.

Xu, B. (2014). Media censorship in China. Council on Foreign Relations, 25.

Yu, Y., Wetzler, A., Yang, X., Tang, R., \& Zhang, L. (2016). Significant and Timely Ivory Trade Restrictions in Both China and the United States are Critical to Save Elephants. Conservation Letters.

\section{Tables}

This article is protected by copyright. All rights reserved. 
Table 1. Coding categories and descriptions used for our sample of online and print news articles taken from the UK, USA, China, Hong Kong and Taiwan.

\begin{tabular}{|c|c|}
\hline Category for classification & Description of category \\
\hline \multicolumn{2}{|l|}{ Main theme } \\
\hline $\begin{array}{l}\text { Is the burn discussed as a positive action for elephant } \\
\text { conservation? }\end{array}$ & Burning ivory is described as contributing to the conservation of elephants \\
\hline $\begin{array}{l}\text { Is the burn discussed as a negative action for elephant } \\
\text { conservation? }\end{array}$ & Burning ivory is described as having detrimental impact on elephants \\
\hline Does the article talk about the burn reducing demand? & $\begin{array}{l}\text { Burning described as an action that will reduce consumer demand for elephant ivory } \\
\text { products }\end{array}$ \\
\hline Does the article talk about the burn reducing supply? & Burning described as an action that will reduce availability of ivory products \\
\hline $\begin{array}{l}\text { Does the article talk about the burn sending a message to } \\
\text { poachers? }\end{array}$ & Article or someone within, states that burning ivory will send a message to poachers \\
\hline $\begin{array}{l}\text { Does the article talk about the burn sending a message to } \\
\text { consumers? }\end{array}$ & Article or someone within, states that burning ivory will send a message to consumers \\
\hline Does the article talk about facts regarding elephant populations? & Article quotes figures on elephant numbers in the wild and associated declines over time \\
\hline \multicolumn{2}{|l|}{ Framing of Ivory Trade } \\
\hline $\begin{array}{l}\text { Is trade proposed as a possible legitimate activity that could be } \\
\text { regulated? }\end{array}$ & Article discusses regulated legal trade as a as a legitimate activity \\
\hline $\begin{array}{l}\text { Is enforcement of trade bans and anti-poaching presented as a } \\
\text { solution? }\end{array}$ & Article presents ivory trade ban and anti-poaching as solutions to elephant decline \\
\hline \multicolumn{2}{|l|}{ Stakeholders Interviewed } \\
\hline Are people involved in illegal trade interviewed? & People such as illegal ivory dealers and poachers \\
\hline $\begin{array}{l}\text { Are people involved in legal trade interviewed (e.g. legal ivory } \\
\text { dealers in China)? }\end{array}$ & Dealers engaging in regulated, certified legal trade in ivory \\
\hline
\end{tabular}

This article is protected by copyright. All rights reserved. 


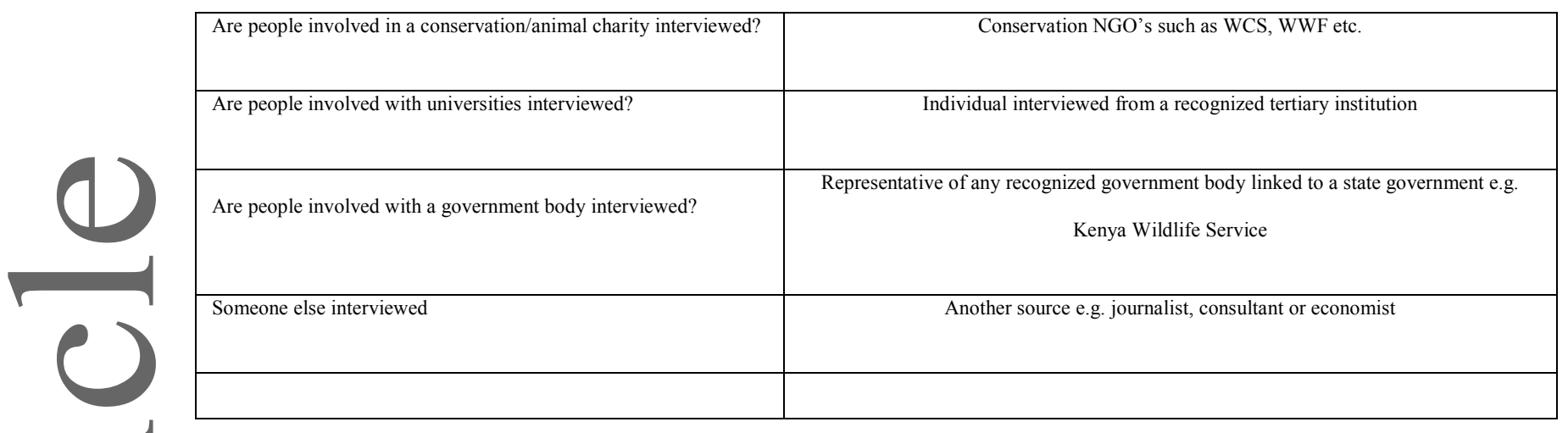

Table 2. Percent of online news articles coded into our 16 elephant ivory burn article categories from our countries of interest.

\begin{tabular}{|c|c|c|c|c|c|}
\hline Category for classification & $\begin{array}{l}\text { UK \% } \\
\text { articles } \\
(n=44)\end{array}$ & $\begin{array}{l}\text { USA \% } \\
\text { articles } \\
(n=49)\end{array}$ & $\begin{array}{c}\text { Mainland China \% } \\
\text { articles }(n=21)\end{array}$ & $\begin{array}{l}\text { Hong Kong \% } \\
\text { articles }(n=7)\end{array}$ & $\begin{array}{c}\text { Taiwan \% } \\
\text { articles }(n=19)\end{array}$ \\
\hline \multicolumn{6}{|l|}{ Main theme } \\
\hline $\begin{array}{l}\text { Is the burn discussed as a positive action for elephant } \\
\text { conservation? }\end{array}$ & 86 & 92 & 97 & 92 & 97 \\
\hline $\begin{array}{l}\text { Is the burn discussed as a negative action for elephant } \\
\text { conservation? }\end{array}$ & 16 & 9 & 4 & 50 & 31 \\
\hline Does the article talk about the burn reducing demand? & 8 & 6 & 11 & 7 & 2 \\
\hline Does the article talk about the burn reducing supply? & 15 & 11 & 2 & 0 & 3 \\
\hline $\begin{array}{l}\text { Does the article talk about the burn sending a message } \\
\text { to poachers? }\end{array}$ & 30 & 37 & 42 & 50 & 47 \\
\hline $\begin{array}{l}\text { Does the article talk about the burn sending a message } \\
\text { to consumers? }\end{array}$ & 11 & 24 & 23 & 35 & 21 \\
\hline $\begin{array}{l}\text { Does the article talk about facts regarding elephant } \\
\text { population size? }\end{array}$ & 33 & 35 & 28 & 71 & 68 \\
\hline
\end{tabular}

This article is protected by copyright. All rights reserved. 


\begin{tabular}{|c|c|c|c|c|c|}
\hline Framing of Ivory Trade & & & & & \\
\hline $\begin{array}{l}\text { Is trade proposed as a possible legitimate activity that } \\
\text { could be regulated? }\end{array}$ & 5 & 5 & 9 & 7 & 3 \\
\hline $\begin{array}{l}\text { Is enforcement of trade bans and anti-poaching } \\
\text { presented as a solution? }\end{array}$ & 62 & 55 & 76 & 100 & 92 \\
\hline $\begin{array}{l}\text { Does the article discuss potential negative } \\
\text { consequences (for elephants) of burning ivory? }\end{array}$ & 36 & 23 & 7 & 50 & 32 \\
\hline Stakeholders Interviewed & & & & & \\
\hline $\begin{array}{l}\text { Are people involved in illegal trade interviewed (e.g. } \\
\text { poachers/ivory dealers)? }\end{array}$ & 0 & 0 & 0 & 0 & 0 \\
\hline $\begin{array}{l}\text { Are people involved in legal trade interviewed (e.g. } \\
\text { legal ivory dealers in China)? }\end{array}$ & 0 & 0 & 4 & 0 & 0 \\
\hline $\begin{array}{l}\text { Are people involved in conservation charity } \\
\text { interviewed? }\end{array}$ & 20 & 12 & 14 & 21 & 3 \\
\hline Are people involved with universities interviewed? & 5 & 2 & 0 & 7 & 0 \\
\hline $\begin{array}{l}\text { Are people involved with a government body } \\
\text { interviewed? }\end{array}$ & 59 & 75 & 76 & 57 & 68 \\
\hline Someone else interviewed? (If so, discuss in notes) & 22 & 21 & 7 & 21 & 0 \\
\hline & & & & & \\
\hline
\end{tabular}

This article is protected by copyright. All rights reserved. 
Figure 1. Motivations for burning ivory from both Kenyan stakeholders directly involved in the 30 April 2016 ivory burn, and also international government and NGO members that extended support for the burn event.

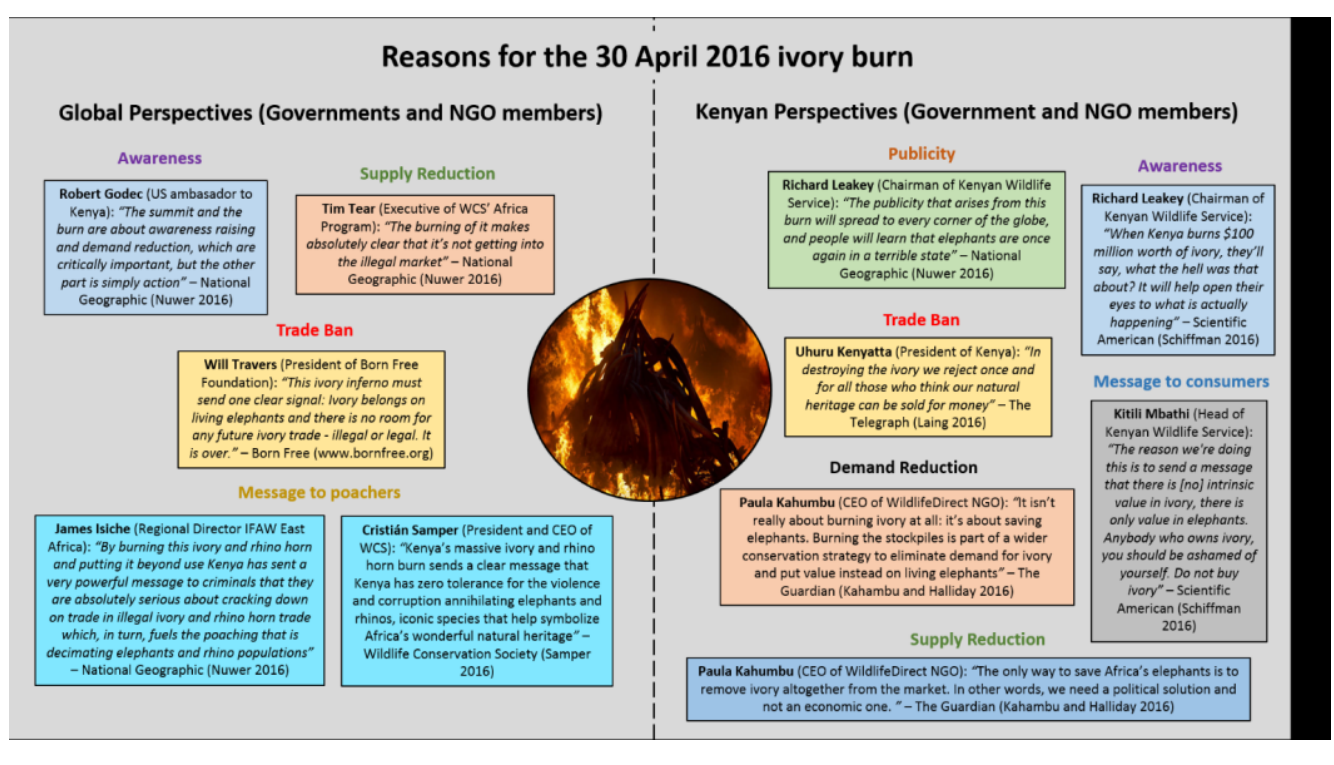

This article is protected by copyright. All rights reserved. 